\title{
Introduction: Is Development Research Communication Coming of Age?
}

\author{
Blane Harvey, Tessa Lewin and Catherine Fisher
}

\begin{abstract}
In this article we reflect on three themes that highlight current trends in research communication for development and, in turn, shape this issue of the IDS Bulletin. We argue that shifts in the sociopolitical and theoretical context within which development research communication is being put into practice; the range and configurations of actors and roles being deployed; and technological advances or innovations available for research communication are affecting important and often contested changes. In introducing this collection of articles relevant to these themes, we conclude that further work is needed in mapping out this evolving landscape and better understanding the interlinkages, antecedents, and tensions between perspectives. Doing so, we argue, could contribute to a stronger praxis of development research communication.
\end{abstract}

Research communication, at least in the context of development, appears contested terrain and means many different things to many people. For some, research communication is primarily a public relations or marketing exercise - as the 'communication' product that comes in the final stages of a linear research process. Increasingly, however, development practitioners and researchers have recognised the importance of iterative and participatory communication processes - which are themselves imbued with value - through which more nuanced products, representative of a greater number of viewpoints might emerge. Quarry and Ramirez (2009) differentiate between 'planners' and 'searchers' in development: those who prescribe big ideas and those who work on small, specific initiatives; those driven more by product and those driven by process. They argue that communication in the context of development should be much more concerned with exploring, enabling, and listening than with prescribing. Similarly, Chandra Mohanty suggests that by listening to the most marginal and disenfranchised communities, we have the most chance of creating an 'inclusive paradigm for thinking about social justice' (2010: 452).

With the advent and multiplication of new communication methods, tools and technologies used at every stage of the research process - from inception to evaluation - the possible meanings and understandings of what constitutes development research communication continues to grow. Together these new configurations have raised awareness of the potential for many more understandings of the roles researchers play in this new environment and the pathways of influence available to them (Benequista and Wheeler, this IDS Bulletin; Cornish and Dunn 2009; Hovland 2003).

In introducing this issue of the IDS Bulletin on communicating research in development we reflect on three dimensions of research communication theory and practice that are driving some of these changes - and which are the focus of many of the contributions to this collection. These are: the evolving social, political and theoretical context within which development research communication is being put into practice; the range and configurations of actors and roles being deployed to carry out research communication in the context of development; and the key role that traditional and emerging technologies are playing in shaping what is possible. These are explored below.

\section{The evolving context of development research} communication

Underlying the production of this issue of the IDS Bulletin is an acknowledgement that both 
the landscape of development and of research communication in development have undergone significant shifts in recent years. Perhaps the most obvious driver of these changes is the rise of new, participatory Information and Communication Technologies (ICTs) that allow for the rapid, multi-sited, multimedia and participant-driven production and communication of research, as it unfolds (Thompson 2008). However, new technologies alone cannot be credited with the changes in the way that research communication in development is conceived and put into practice. There are underlying shifts in the politics and business of development knowledge that have played a key role in either encouraging or discouraging innovation and new approaches. We highlight three such shifts here: the pluralisation of 'expert knowledge' in development; growing emphasis on process (as opposed to product) in development research; and new understandings of what drives social change and policy influence.

The divergent perspectives and approaches noted above sit within a rapidly changing environment where traditional understandings of what constitutes 'knowledge', 'power', and 'validity' are being challenged or overturned. What does validity mean in an environment where bloggers and journalists are often viewed as more credible, useful or accessible sources than researchers? How are the roles of researchers and research communicators changing?

Our evolving notion of what constitutes expert or valid knowledge is not a new phenomenon, but when considered alongside the other trends discussed below, it has had a profound effect on approaches to communicating development research. For development research institutes in the global North, such as the Institute of Development Studies, it has significantly affected its models of research, partnerships, funding, and communications, bringing an increased focus on knowledge sharing, social learning, and the roles of intermediaries and networks alongside more traditional 'development research' activities. This has been further influenced by increasing attention to knowledge co-production, in-country spend of development finance, applicability and 'uptake' of research, and the importance placed by some on local capacity development and local knowledge.
These shifts have also meant that communicating development research has, for many, become as much about process - translating, synthesising, and communicating knowledge from a range of sources into new forms for diverse audiences and outcomes, often in direct collaboration with the holders of that knowledge - as it is about product. This tension between process and product as points of focus can be both productive and problematic, as learning, exploration and empowerment take on new levels of importance, but sometimes at the expense of the gloss and visual impact of 'standard' communications expected by some. Similarly, tensions may also emerge between research communication processes that bring about positive impact for those engaged in the processes themselves and the desire to have communications products produce impact amongst policymakers or other actors external to these processes, as the two may not be mutually achievable (see Scott-Villiers, this IDS Bulletin). This raises important questions about the different underlying motivations for undertaking research communication in development, and how potentially competing aims of communication for awareness-raising, social or political influence, self-promotion, etc. are often expected to be addressed within a single approach.

Finally, understandings of policy influence in research and communication have, for some, evolved away from solely linear and top-down models of influencing (e.g. getting research onto the desks of the most senior decision-makers), toward more complex and multi-sited theories of change. Recent evidence pointing to the contributions of grassroots and social media as drivers of political change, notably in the 2011 Egyptian uprisings have sparked considerable reflection on how to understand or engage with the power of 'unruly' politics (or political action that unfolds outside the realm of formal political space) (Khanna 2012) and influencing from below. Further, within more formal research-policy interfaces such as research institutes and think tanks, a more complex reading of policy influence and of how research may, or may not lead to evidence-informed policy is emerging.

Despite our broadening understandings of the role and potential of research communication in theory, challenges remain, among them: a return to positivistic and linear understandings of 
research influence within some circles, and a lack of clarity with regard to the objectives, outcomes and impacts development research communication should achieve. Jacobson has situated contemporary development communication in the 'wake' of positivism, arguing that 'while positivism may be declared philosophically dead its effects still seem evident in textbooks, in the research agendas of many communication researchers and indeed certainly in those of funding agencies' (1996: 80). Indeed, we would suggest that the current trend today in many circles is for a return to positivist models of reason, evidence and analysis, a trend that has created additional challenges and divides. There remains a strong alignment of development research communication with early modernisation and behaviourist theories of communication influence which are evident in approaches to social marketing, health communication, and edutainment used in development today (Waisbord 2001).

Mainstream approaches are also increasingly output-driven, with an underlying (and often unacknowledged) presumption that influence is linear and should be overwhelmingly targeted at policy audiences. There is a clear disjuncture between this 'dominant paradigm' of approaches (ibid.), and the rich diversity of practices and understandings of communication at our collective disposal.

Further, many donors and institutions driving research agendas assume that policy targets and processes can be directly influenced by research communication, and there is resurgence of focus among many of them on measuring and attributing its 'impact' - though this is notoriously difficult to do (Sumner et al. 2009) and is seen by many to be oriented primarily to donor interests (Jones et al. 2009). There is also an assumption among some actors that research communication is an often an unnecessary addon, or a dispensable luxury. As a result, research communication processes are often constrained by demands to deliver only what offers directly attributable value for money and is deemed essential to the outcomes of development activities ( $c f$ Lewin and Patterson, this IDS Bulletin). On top of this, there is lack of clarity or consensus on the meanings of research impact or influence, and researchers have very different ideas about who they are trying to influence, to what end, and using which methods.
Glearly, however, none of these trends have been unidirectional, and some have been met with ambivalence or outright resistance. With the rise of participatory and co-constructed communications on climate change for example, has come suggestions that we have neglected the scientific rigour needed to influence policy. Concerns about the rise of one-dimensional valuations of research evidence and use have been met with a 'Big Push Forward' by theorists and practitioners concerned with these framings. ${ }^{1}$ As such, development researchers and communication specialists find themselves at a point of juncture, with competing interpretations of the most effective pathways to producing social change in the context of complex and multi-sited development challenges.

\section{Actors, networks and relationships}

The forces outlined above have also prompted a proliferation in roles and actors for communicating research in development. These new roles push the boundaries of conventional ideas of research and are challenging how research agendas are set, and how knowledge is generated and shared. For some researchers this is bringing work they have always undertaken into focus and in some cases legitimising it, for others it implies new and unfamiliar ways of working. In this context, researchers are being joined by other actors, such as research communication specialists, not necessarily involved in undertaking research, who seek to strengthen use of research in change processes. However, this may not always be a straightforward relationship. Differences of viewpoint may exist between researchers and communication specialists owing to limited experience in working together and different understandings of the relationship between research, communication and influence as a linear (as opposed to systemic) process.

Another set of roles that are proliferating are those concerned not with the influence of a particular set of ideas, but with enabling effective use of a broad range of information and knowledge for decision-making and change. These roles are held by neither researcher nor decision-maker, but instead by actors seeking to strengthen the linkages and flows of information between disciplines, areas of practice or sources of knowledge. Actors playing these roles can be described as information intermediaries 
Figure 1 The spectrum of intermediary and brokering functions

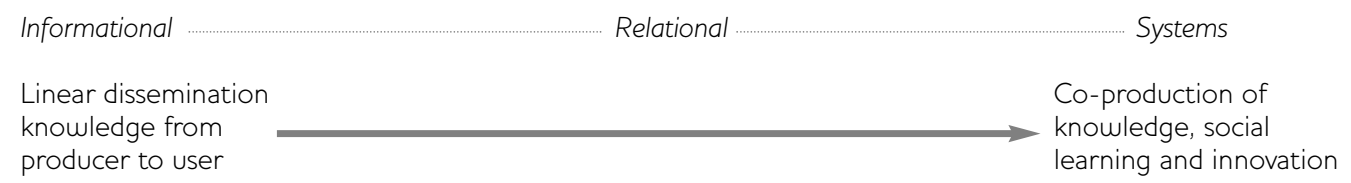

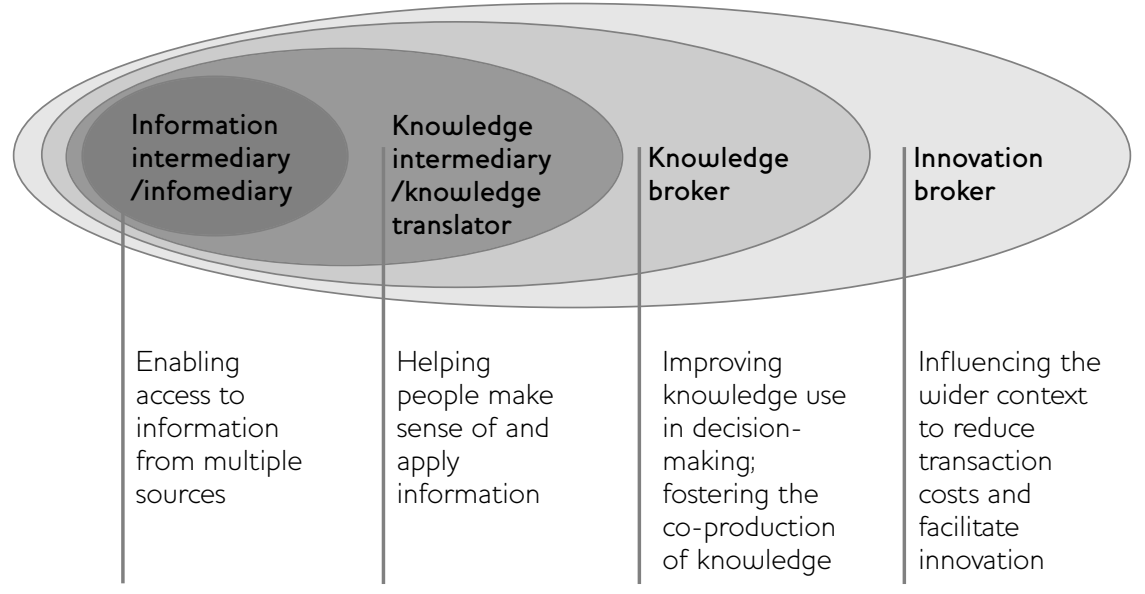

Source Adapted from Fisher (2011).

(info-mediaries) (Fisher and Kunaratnam 2007), knowledge brokers (Lomas 2007) and innovation brokers (Klerkx et al., this IDS Bulletin). The language to describe these roles and actors varies, reflecting the diversity of backgrounds, origins and drivers for the work.

The range of information intermediary and knowledge broker roles (however they are described) are broad (see Figure 1). Some are concerned with information flows, others about repackaging information, still others with brokering relationships and knowledge sharing, and yet others with brokering systemic change processes. Perhaps the most visible testament to the growth of these kinds of roles within the development sector can be seen in the plethora of portals containing research information, and in the proliferation of communities of practice and knowledge-sharing networks, both of which exist at national, regional and international levels.

Interest in brokerage and intermediary activities as part of (or complement to) research communication for development lies in their potential for enhancing both the 'producer push' of research and the 'user pull' for research, often with an explicit emphasis on the latter. In doing so they can support evidence-informed decision- making (whether in policy or practice) as opposed to direct policy influence by knowledge producers ( $c f$ Newman et al., this IDS Bulletin). They can extend the reach of research messages or archive them for future reference; they can help those seeking information to navigate an increasingly complex information environment; they can champion less powerful voices and foster connections that might not otherwise be made and enable discussion that might not happen.

However, in the strengths of these kinds of roles also lie their weaknesses. Intermediaries and brokers have been accused of acting as gatekeepers, deliberately or inadvertently privileging certain perspectives over others, their claims to objectivity are challenged as masking hidden agendas (Fisher 2010). Some models of knowledge brokerage are also critiqued for overly linear and apolitical ideas about the connection between information knowledge and change. These challenges are exacerbated by interrelated factors: the diversity of people playing the role, the fragmentation of the sector, and the apparent lack of theoretical grounding upon which much of the work rests (Bielak et al. 2008).

These new and reinvented roles are increasingly a part of the broad spectrum of research 
communication and although contested by some, are unlikely to disappear. As such they merit greater attention, by donors, by those studying the interfaces between research and change and most importantly by the people playing these roles themselves.

\section{Communication technologies: transforming development research and practice?}

The expansion in the range of approaches to, and roles in communicating research for development, is mirrored, and to some extent led by a surge in new communication technologies. Research communication is both professionalised and democratised by the new ubiquity and affordability of these new tools. However, as old and new media converge, we see a reconfiguration of old hierarchies. As development and research actors increasingly fixate on new technology and its assumed capacity to drive change, so those wary of technological determinism caution against overemphasising the agency of technologies. The dubbing of the early days of the Arab Spring in Tunisia as 'The Twitter Revolution' caused an outcry from those who reminded us that people, not technologies, lead revolutions.

Berdou's work argues that although new technologies are introducing new opportunities and actors into the development field, their newness often comes with fairly unproblematised assumptions about the relationship between information and action: 'For the more technologically determined this relationship is direct: increased access to information can support citizen action and seed positive social change... For development researchers this connection is not evident' (2012: 6). She also notes that although 'open knowledge' technologists and participatory researchers appear to share 'language, values and priorities... their trajectories rarely intersect' (ibid.: 1), suggesting that the two have much to learn from each other.

But, there are some irrefutable changes - nearly 90 per cent of the world's population are now covered by mobile phone signal. ${ }^{2}$ Increasingly sophisticated visual methods, networking tools, and data collection tools give us access to different forms of knowledge. People are building ICT-enabled alliances around types of influence they want to have on political economies. New technologies are being used not just to study reality but also to open up other realms of the possible. Mason (2012) notes that it's not the technologies themselves that are interesting but the ways in which they are being used, and what these technologies do to hierarchies, ideas and actions. Facebook is being used to foster networks and build connections. Twitter is used for real-time organisation and dissemination. YouTube and Flickr are used to show visual and contextual evidence, and present more in-depth arguments to support these networks.

Other examples of how new technologies are opening opportunities for innovation in development action abound: mobile phone software allows farmers in rural Ghana to check on current crop prices before selling their produce. Mapping technology in Haiti and Palestine is used to help relief workers to quickly access hard-hit communities. Mapping and crowd-sourcing technology in Kenya have transformed the map of Kibera, Nairobi from a forest into a busy urban slum. Researchers in the Chittagong Hill Tract region of Bangladesh are using computers to help women construct their own digital stories allowing us an insight into their everyday realities.

Perhaps most important is the capacity for new technologies to aggregate, and augment information, to rapidly network people, and to dissolve or disrupt old hierarchies. Brooke (2011) argues that we are in the age of 'Information Enlightenment' where technology is challenging traditional barriers including class, power, wealth and geography in favour of an ethos of collaboration and transparency. However, some have argued that the democracy these technologies claim to foster is a myth (e.g. Hindman 2008) whilst others argue that with the disruption of old hierarchies, comes the introduction, or further reinforcing of new ones (Alzouma 2005). With the increasing regulation and policing of social media and other communication platforms, their uses cannot be assumed to be benign. State departments have created 'sock puppets's or impersonated others to spread government propaganda. People hijack identities and stories for their own uses. It is often difficult to recognise what constitutes a legitimate source, and there is a danger of misconstrued meanings as content is reused and remixed and taken out of context. Ethics can be murky as we enter new territory, and the benefits it brings research communication in terms of pluralisation 
of voice, democratisation of participation, and innovation in content creation must be weighed against the more cautionary notes raised above.

\section{Introducing the articles}

The contributions to this issue of the IDS Bulletin bring together new reflections on these areas of inquiry, and the debates that are enmeshed in them. Drawing upon a wide range of fields of development practice, the contributions themselves reflect the overlaps and disconnects within different fields, and particularly with a common aim of critically reflecting on how new technologies, approaches and configurations of research communication are influencing the practice of development. The contributions sit, at various points, in tension or consensus with one another, reflecting the unresolved nature of the politics and practice of research communication - but together they begin to map a complex picture of this arena.

In the first section of articles, authors reflect critically upon the changing context within which research communication for development now unfolds and suggest ways in which this might reshape our practice. Datta, in his opening contribution, emphasises how new understandings of complexity in development are forcing researchers to integrate deliberative and co-constructive approaches to communication into the core of their practice. Similarly, Harvey et al. look at the specific case of climate change communication within an international science institution and argue that learning-centred approaches to communication are essential for development challenges that are marked by high degrees of complexity and uncertainty. The pieces by Newman $\boldsymbol{e t}$ al. and Scott-Villiers offer two compelling and contrastive reflections on the role of research and evidence in shaping policy: one reiterating the value of evidence-informed policy but reflecting on issues in challenges in strengthening the capacities required to act on it; the other underscoring how research falling outside of the realm of what is seen to be 'policy relevant' can bring important contributions to other aspects of development and social change. Finally, Lewin and Patterson trace the coevolution of models of research communication and development, reflecting on how creative and visual methods fit into this trajectory and arguing that the increased accessibility of communication technologies has emerged alongside a revival of more linear, marketingstyle understanding of development research communication, which threatens to undermine their progressive potential.

In the second section of articles, contributors reflect on the expanding range of roles and actors engaged in contemporary research communication for development. Benequista and Wheeler begin by offering a typology of some of these roles, drawing on a ten-year research programme, with an aim of clarifying our understanding of how knowledge produced by research is put into use, and to illustrate the range of approaches we might take in research communication. Davies et al. provide an example of one of these roles, describing how Kenyan scientists (to their surprise) learnt from school students (both contextual findings and about their own research) after entering an engagement process to raise others' awareness of their research and promote positive attitudes towards science. Klerkx et al.'s contribution reflects on how some of these roles in the context of agriculture and development build on and overlap one another over time. They compare the evolving roles of innovation and knowledge brokers, arguing for a greater awareness of the contributions innovation systems approaches might make to knowledge brokerage in development more broadly. Beynon et al. then share findings from a study of how different types of policy briefs are engaged with by readers - and the lessons this reveals about the influence of perceived expertise and opinions on decisions made by those engaging with knowledge products, and revealing how readers' non-linear treatment of research evidence challenges the received wisdom of certain practices.

The final section of this IDS Bulletin looks more explicitly at the role that particular technologies and technological innovations are playing in reshaping the practice of research communication in development. Gilberds and Myers begin by looking at how the convergence of radio with new ICTs is reshaping the use of this more traditional technology, but also how this convergence changes the roles of broadcasters as knowledge intermediaries. Batchelor then describes the way in which research was able to directly influence the development of mobile phone technologies and practices in relation to money transfers in Africa. Following this, a series 
of articles from Worcester, Rahim, Hallez and Lewin all look at the ways in which different technologies were used in a wide ranging Women's Empowerment programme to broaden and deepen research communication. Lewin makes an argument for the added value of the use of documentary film in development research communication. Worcester and Rahim both assess the same group of digital storytelling workshops, held in Bangladesh. Worcester looks critically at the framing of the workshops and situates the work theoretically while Rahim gives a more detailed analysis description of the workshop process. Hallez then writes about a photography competition held just prior to the Egyptian revolution, aimed at exploring how to re-present women's empowerment. She argues that this kind of participatory development communications encourages nuance and complexities and allows for a richer understanding of empowerment, than more linear models might give. Finally, Davies and Edwards describe the rise in open data initiatives, and consider the impact this is having or may have on knowledge and power dynamics in development, as well as the challenges it may entail for development researchers and practitioners.

\section{Some final thoughts}

The title of this introductory article asks whether development research communication is coming of age. While we see a rapid proliferation of theory-building around what constitutes this field, we argue, building on Waisbord and Jacobson above, that although there are numerous approaches to communication, there is very little tolerance between them and that there remains a

\section{Notes}

1 See www.bigpushforward.net (accessed 27 June 2012).

2 See www.itu.int/ict/statistics (accessed 27 June 2012).

\section{References}

Alzouma, G. (2005) 'Myths of Digital Technology in Africa: Leapfrogging Development?', Global Media and Communication 1: 339

Berdou, E. (2012) Participatory Technologies and Participatory Methodologies: Ways Forward for Innovative Thinking and Practice, IKM Working Paper, http://wiki.ikmemergent.net/files/1202Berdou_IKM_27022012.pdf (accessed 2 July 2012) need for greater understanding from across disciplinary and epistemic divides. Jacobson (1996) points, for example, to anti-positivists who define themselves in unhelpfully 'obsessive' opposition to empirical, quantitative methods, while Waisbord highlights a continued rift between behaviouralist and participatory approaches 'despite the cross-pollination of traditions and a multi-strategy approach to interventions' (2001: 35).

We argue that while initial efforts have been made to map the scattered terrain of approaches to communicating research for development (cfJones 2009; Waisbord 2001), further work is needed to bring together this disparate, yet often overlapping or contradictory body of practice. Further, more work is needed to disentangle the multiple ends of development research communication and better understand whose interests these serve, and how different approaches will and will not achieve them. Efforts to map this field of action shouldn't be seen as striving towards a neat synthesis, but rather toward a greater understanding of the interlinkages, antecedents, and tensions between perspectives. Building on this, a better understanding of the practical ways that these perspectives and approaches play out in practice - as illustrated through case studies and empirical or experiential evidence - may lead us toward a stronger praxis of development research communication. The rich range of experiences shared through the contributions to this IDS Bulletin represent, in our view, an important step in achieving this.

3 A false online identity, typically created by a person or group in order to promote their own opinions or views (Oxford English Dictionary).

Bielak, A.T.; Campbell, A.; Pope, S.; Schaefer, K. and Shaxson, L. (2008) 'From Science Communications to Knowledge Brokering: The Shift from Science Push to Policy Pull', in D. Gheng, M. Claessens, T. Gascoigne, J. Metcalfe, B. Schiele and S. Shi (eds), Communicating Science in Social Contexts: New Models, New Practices, Dordrecht: Springer: 201-26 
Brooke, H. (2011) The Revolution will be Digitised: Dispatches from the Information War, London: Heinemann

Cornish, L. and Dunn, A. (2009) 'Creating Knowledge for Action: The Case for Participatory Communication in Research', Development in Practice 19.4-5, London: Routledge

Fisher, C. (2011) Knowledge Brokering and Intermediary Concepts: Analysis of an e-discussion on the Knowledge Brokers' Forum, http://assets00.grou.ps/0F2E3C/ wysiwyg_files/FilesModule/knowledgebrokers forum/20110721104502-ugrvcfpatmivjojwi/ Knowledge_Brokering_and_Intermediary_ concepts_discussion_Summary.pdf (accessed 3 July 2012)

Fisher, C. (2010) How Research Brokers and Intermediaries Support Evidence-based Pro-poor Policy and Practice: An Analysis of the Locating the Power of In-between Conference, 1-2 July 2008, Pretoria, South Africa, Pretoria: Human Sciences Research Council, www.hsrc.ac.za/ Research_Publication-21525.phtml (accessed 27 June 2012)

Fisher, C. and Kunaratnam, Y. (2007) Between Ourselves: The New Generation of Information and Knowledge Intermediaries, Brighton: IDS, www.ids.ac.uk/files/Between_ourselves_report. pdf (accessed 28 June 2012)

Hindman, M. (2008) The Myth of Digital Democracy, Princeton University Press

Hovland, I. (2003) Communication of Research for Poverty Reduction: A Literature Review, ODI Working Paper 227, London: Overseas Development Institute

Jacobson, T. (1996) 'Development Communication Theory in the Wake of Positivism', in Jan Servaes, T.L. Jacobson and S.A. White (eds), Participatory Communication for Social Change, London: Sage
Jones, H. (2009) Policy-making as Discourse: A Review of Recent Knowledge-to-policy Literature, Joint IKM Emergent-ODI Working Paper, London: IKM-Overseas Development Institute

Jones, N.; Jones, H.; Steer L. and Datta A. (2009) Improving Impact Evaluation Production and Use, ODI Working Paper 300, London: Overseas Development Institute

Khanna, A. (2012) 'Seeing Citizen Action through an "Unruly Lens", Development 55.2: 162-72

Lomas, J. (2007) 'The In-between World of Knowledge Brokering', British Medical Journal 334.7585: 129

Mason, P. (2012) Why it's Kicking off Everywhere: The New Global Revolutions, London: Verso Mohanty, C. (2010) 'Under Western Eyes Revisited: Feminist Solidarity through Anticapitalist Struggles', in C. McCann and S. Kim, Feminist Theory Reader, New York: Routledge

Quarry, W. and Ramirez, R. (2009) Communication for Another Development: Listening Before Telling, London: Zed Books

Servaes, J.; Jacobson, T. and White, S. (1996) Participatory Communication for Social Change, London: Sage

Sumner, A.; Ishmael-Perkins, N. and Lindstrom, J. (2009) Making Science of Influencing: Assessing the Impact of Development Research, IDS Working Paper 335, Brighton: IDS

Thompson, M. (2008) 'ICT and Development Studies: Towards Development 2.0', Journal of International Development 20: 821-35

Waisbord, S. (2001) Family Tree of Theories, Methodologies and Strategies in Development Communication, paper prepared for the Rockefeller Foundation, New York: Rockefeller Foundation 